\title{
The Human Dimension on Distance Learning: A Case Study of a Telecommunications Company
}

\author{
Marina Keiko \\ Nakayama and \\ Bianca Smith Pilla \\ Universidade Federal \\ do Rio Grande do Sul, \\ Brazil
}

marina@ea.ufrgs.br bspilla@ea.ufrgs.br

\author{
Erlaine Binotto \\ Universidade Federal do \\ Rio Grande do Sul, Brazil \\ and \\ The University of \\ Queensland, Australia
}

erlaine@vortex.ufrgs.br

\author{
Ricardo Azambuja \\ Silveira \\ Universidade Federal \\ de Pelotas, Brazil
}

\begin{abstract}
This paper describes a case study concerning the human dimension in a Distance Learning (DL) program implemented at a telecommunications company in the state of Rio Grande do Sul, Brazil. The objective was to identify how the company addresses this perspective in the administration of their DL System. To attain the proposed objectives, documentation techniques, direct observation and interviews were used. The findings reveal that only some human aspects of DL are receiving priority in the company. It is reported that the DL have some problems of the traditional training and new problems as well. The research points out that a new learning model directed to knowledge build-up is needed.
\end{abstract}

Keywords: E-learning, Distance Learning, Virtual Training, Human Dimension and Technology.

\section{Introduction}

The history of administration reveals that the greatest concern for the people in organizations first appeared in the 1930's, in opposition to the mechanistic paradigm of the scientific management and classical theories, which were first advanced by Taylor and Fayol. The research done by Elton Mayo about the productivity of the employees in the Hawthorne demonstrated that people are motivated to work by social and psychological factors and not only by salaries. This was the beginning of the Human Relations (HR) theory in which employees start to be seen as people and the organizations consider them as a fundamental factor in productivity, although the importance of the human aspects was not universally recognized.

At the present, due to the complexity of organizations, a number of organizational studies are appearing that do not yet constitute acknowledged theories, but indeed deserve much attention. What stand out are the researches on Organizational Culture, Apprenticeship, Innovation, and

Material published as part of this journal, either on-line or in print, is copyrighted by Informing Science. Permission to make digital or paper copy of part or all of these works for personal or classroom use is granted without fee provided that the copies are not made or distributed for profit or commercial advantage AND that copies 1) bear this notice in full and 2) give the full citation on the first page. It is permissible to abstract these works so long as credit is given. To copy in all other cases or to republish or to post on a server or to redistribute to lists requires specific permission from the publisher at Publisher@InformingScience.org
Creativity, among others, with contributions to the Administration from several sciences: Sociology, Psychology, Economics, Pedagogy, Computer Science, and more.

Organizational behavior studies bring up the human matters in organizations. To study the human aspects in 
the organizations (motivation, change in behavior, desire, symbolism, communication and speech, perception of space and time, leadership, individual singularities, participation and consideration, and learning) permits a greater comprehension of people, their feelings, interactions, and reactions to changes. Thus, the human aspects should be considered in the Human Resources policies so that the employees and the company may both achieve their strategic goals.

Nevertheless, history also reveals that when employees are attempting to upgrade their professional capacities, some organizations have claimed that priority must be given to the objective aspects (costs, logistics, needs assessments, evaluation...) to the detriment of the human aspects. On the other hand, historically, many organizations acknowledged the strategic importance of Training and Development. Therefore, organizations have been investing heavily in the capacity of their employees. The skills and knowledge of latter must be continuously updated so that they may keep up with the speed of change with efficiency.

With this growing need for people qualified, every day there appear new information technologies that can be combined with modern education techniques, thus permitting improvements in human learning and work performance. One option used in company training is Distance Learning (DL). This learning-apprenticeship modality is being applied more and more to increase the capacity of employees.

The utilization of a Distance Learning System presents advantages, such as the access to a greater number of people, the integration of many educative resources, respect for the student's own rhythms of work and learning, continuous updating, and a reduction on educational costs (Niskier, 1999). On the other hand, owing to the fact that it is a recent application system in companies and despite the several studies about its organizational impacts, knowledge about DL systems are still insufficient. Research in general so far has taken in account the mainly technological aspects of DL and, in some situations, the matter of apprenticeship.

This is so in the case of the company investigated, since 1996, it has implemented and consolidated a DL System, which delivers several training programs to their employees. This company in the telecommunications business, where changes are swift and technologies rapidly become obsolete, demonstrates concern in overcoming the barriers of space and time. It is also striving to make the capacity of its employees more flexible in order to maintain its leadership in the market and achieve its goals.

This telecommunications company is a pioneer in this matter with its DL System, which has been acknowledged in the business and academic area. DL system has been the subject of many awards, and of representations at conventions and events. It has also been studied by Guerrero Nakayama, Verdin, and Pilla (2002), who identified the changes unleashed with the implementation of DL in this company. The authors recommended that there should be a study on the human dimension as of the system; their analysis suggested that it should be given more importance.

Thus, this work follows on from the study done by Guerrero et al. (2002) with the aim of investigating the human aspects in the company's DL program, improving the system and the satisfaction of its users. The specific objectives are as follows:

- Describe the company's DL System

- Identify how the DL specialists, leaders and employees of the company perceive the human aspects in the DL System

- Compare the perceptions of the DL specialists, leaders and employees of the company about human aspects in the DL System

- Relate the weak points and opportunities for improvement in the DL System regarding the human aspects 
This paper will provide and outline of the concepts and definitions that guided the research. Followed by a description the methodology applied in the research and the main results. Lastly, the final considerations will be presented.

\section{Distance Learning}

The Distance Learning concept has been well debated among researchers and professionals in the area; as the term implies, discuss the conception on education (and consequently that of teaching, training, and apprenticeship) and distance (physical or temporal). There are also other similar terms, such as "Distance Education”, "Distance Training”, “Tele-education”, "Virtual Training”, and "E-learning", which can be used for precision in discussing in distinct situations according to the technologies employed and the context in which they are applied. The term "Distance Learning” has been well applied in organizations. However, the different DL definitions frequently present contradictory aspects and are confounded. Vargas (2000) suggests it that the introduction of information technology in DL makes it necessary to re-structure the many concepts from earlier DL systems still in use.

Spodick (1995) defines DL as a system that should provide all and any educational opportunities that may be necessary for almost anyone, in any place, and at any time. According to Moore \& Kearsley (1996, p. 11), DL is a planned learning that normally occurs in a number of teaching site and requires special techniques of course design, special instruction techniques, special communication methods through electronics and other technologies; just as essential are special organizational and administrative arrangements.

Cardoso \& Pestana (2001), present another more concise DL definition. They believe that in DL, the information or source of knowledge is separate from the student or teacher in Space or Time. Therefore, the DL concept in this research is that done by Moore \& Kearsley (1996), complementary to the ideas of Cardoso \& Pestana (2001).

The means used in DL may be classified into classic and contemporary. Kramer and Coester (1999) mention the following classic instruments: printed material, mail, radio, television, video, audio, telephone, fax, and videoconference.

One of the main technologies utilized in DL nowadays is CBT (Computer Based Training). With the advent of Internet, it has become WBT (Web Based Training) with complete monitoring, such as name, web address, access counter, content progress counter, evaluation results, etc. However, the main WBT restriction is that of the conventional telephone line connections that are rather slow for accessing audio and video resources.

According to Cardoso \& Pestana (2001), the Internet is making the means of communication more potent and, as a consequence, the many methods of training interventions are becoming more effective. It makes available the correct and necessary information at the right time for each individual's needs. This way the Web becomes a modern technological tool to make DL practical. The big advantage in using the Internet in DL is the fact that it is a bi-directional channel, that is, there are two communication routes: one to transmit information to the student and another from the student to the instructor.

According to Cruz \& Moraes (1998), the Internet promotes a greater interaction between student and teacher and student and student it is a space for collective knowledge and information exchange and production apart from class schedules and through videoconferences. This interaction occurs through the WWW site or even through the company's Intranet for the participants' use. The authors also mention that in the site are encountered the necessary tools for the student to communicate with the teachers or class-mates, talk about classes, discuss topics related to the dis- 
ciplines, send assignments to the teacher and access discipline rolls, reference bibliographies, articles and other important information for a satisfying performance in the course.

The World Wide Web has practically become a synonym for the Internet. According to Nakayama, Silveira, \& Pilla (2000), in the WWW sites are found resources with texts, lessons, figures, films, communication instruments, and more. The students can receive a login and a password to access the course page, get the tasks and contents, interact in chats for information exchange, participate in discussion lists through e-mail and forums with classmates, and send and accomplish course activities. In some cases they may join in a present class (physically contact) to review the contents and for evaluation of the course.

The Internet also brings forth many learning opportunities that may be useful for DL. The main means are e-mail, discussion lists, news groups, chat, video under demand, and Web TV. All these solutions in DL have the purpose of increasing the diversity of learning possibilities but will not substitute for the conventional methods of corporation training.

Cardoso \& Pestana (2001) also mention that there are present courses with virtual discussions and virtual content deliveries with present discussions that they refer to as "Integrated Solutions". In a general sense, the integrated solutions (also known as hybrids) have been achieving good results in organizations once they reinforce the participant's compromise.

\section{The Human Dimension}

In general, the classic writers ignored the human element. The origin of the organizing thought is the belief that rationalism provided an extremely limited aspect and was a frequent cheater of the "realities" of the organizational life (Reed, 1998). Rationalism enhanced order and mechanically imposed control but ignored the benefits of integration, the inter-dependence, and the balance in organic development that should exist in social systems.

This classic approach tried to maximize organizational efficiency through analysis and control of tasks (Taylor, 1990) and structure (Fayol, 1989). However, while these theories resulted in increased efficiency as empiricism and improvisation were replaced by scientific techniques, the mechanistic view on which they were based was extended to human beings as well.

It was then that some researchers realized that the rationalist organization was unable to solve social integrational problems. In the 30's, Mayo (1933) accused the rationalist tradition of ignoring the natural and evolutional qualities of the new social environments created by industrialization and developed a humanistic school, of which the main point is recognition of the human dimension in administration.

In this sense, Motta (1998) analysed organizational changes under six perspectives, notably human perspectives. In his studies on these changes, he examined the main organizational conceptual models and the respective means of change and the instruments with which they are associated.

The humanistic perspectives see the organization as a collection of individual groups. Its principal aspects are the objectives and individual self-achievement, behaviour, personal and group interactions, and informal organization. Nowadays, when organizations are characterized by a greater technological uniformity and by rivalry, the concern with the human dimension has become more intense. Many companies assert that their competitive advantage is no longer technological, but that of human resource quality. Thus, the administration of human resources acquires strategic importance and makes use of new practices. The challenge is to render favorable work and learning the new functional environments to find new ways to attract and maintain employees, the individuals' entire development and changes in direction in order to help the worker achieve professional satisfaction, progress and a rewarding career (Motta, 1998). 
In this context, human behavior has become an important line in research in organizations. The topic was raised first by researchers in the disciplines of psychology and sociology, and only recently by administration schools. Chanlat (1996) directs his studies upon the individual in organizations to different aspects, which he refers to as the "forgotten dimensions". His contributions are summed up as follows:

- The individual is a generic and singular being: the individual is unique above and beyond the analysis of the disciplines that study him. He is a bio-psycho-social being, whose elements are intimately linked. Thus, the reductionism does not make sense. It is necessary to comprehend the human being in his totality. As he is a generic being who is part of the human race, he is also at the same time unique, whether man or woman, child or adult, peasant or worker, and so forth. Thus, the study of people humans in organizations cannot be separated from this double dependency, the needs of individual and social beings.

- $\quad$ The individual is an active and reflective being: this means that the human being has the capacity to think and act. The human being is an individual because of his acts that build up his own social reality. Therefore the importance of observing the subjectivity in action and perception of the organizational universe.

- $\quad$ The individual is a being of words: the human being can express reality in words and is inserted in a world full of meanings. Language is the element that permits us to reveal conducts, actions, and decisions. One must consider that every speech, every word, and all documents are inserted in the sphere of acting, making, thinking, and feeling.

- The individual is a being of desire and impulse: the human being cannot be reduced to an organism subjected to a continual bombardment of stimuli. He is also a being of desire, impulse, and relationships.

- $\quad$ The individual is a symbolic being: each human being and all human society produced a representation of the world that confers meaning through signs, images, metaphors, emblems, symbols, myths, allegory, and more. It is necessary to realize that an organization is a favorable place for the emergence of symbols.

- The individual is a temporal-space being: each human being is inserted in space and time; however, perceptions are different. Every human being has some kind of link with space, the function of which is to reaffirm his identity. In this context, the organization is one of these links.

- $\quad$ The individual is the object and subject of his science: the study of human being id different from the exact sciences, because the research cannot analyze him as an inert object for he is at the same time object and subject of his science.

Once all these matters related to the individual are acknowledged and become objects of analysis, doors open to less explored matters in organizations. One such case is apprenticeship. The human aspects of this research have an intimate relationship with learning. For this reason it is important to describe this relationship. One may say that learning is the main objective of any DL program and this, without doubt, influenced by the human dimension.

Peters (2001) deals with two significant changes in education: from traditional learning to distance learning and from distance learning to on-line learning. According to Peters, the first change is a consequence of an "industrialization" process in education. The second is examined under a comparative interpretation of real and virtual learning spaces.

In virtual learning, instruction behaviors differ from those in real learning spaces. This new learning model enhances learning "through discovery" and "through the solution of problems". 
After analyzing the origin of DL, Peters affirms that at the time there were commercial reasons for the creation of DL and that its purpose was merely to increase the institution's profits. As a consequence an established and formalized standard learning came into being was offered to all participants of the course, who could repeat it as many times as necessary. Learning became a product that could be altered and perfected. Above all, it could be sold almost anywhere. Thence, Peters applies the term "industrialization" to education.

Peters, however, realizes that industrialized learning today is not adequate anymore. Distance learning must be considered, in structural terms, a distinct learning system. People want varied and specific possessions, that is, "smaller" courses of short duration that may be altered and renovated rapidly.

In such matter, Peters considers the use of virtual learning as the most fundamental pedagogical happening of the moment, an event that has a cultural and historical importance. As source which could contribute to the development of a virtual learning model, Peters points to Cognition Psychology based on the individual development of thought; to Constructivism, that interprets learning as individual development and the constant change in cognitive structures; and for certain pedagogical models of higher education, which enhance the orientation of the student, learning by means of discovery, self-learning, independent learning, collaborative learning, and learning based on resources or financial support.

\section{Research Method}

The research method adopted is the Case Study. It comprised interviews with 20 people belonging to different professional segments in the company:

- 7 DL specialists

- 4 leaders (coordinators, managers, and directors)

- 6 employees who had completed a course through the DL System in the company

- 3 employees (non-specialists in DL) with additional information relating to the system

The decision to listen to these different groups was intentional with the idea of obtaining a wider range of views and comparing the different perspectives on the human aspects of DL in the company. All participants were volunteers.

Besides the interviews, documentation and direct observation techniques were applied, which combined to establish validity and credibility for the study case. The period of data collecting extended from February to August of 2002.

The questions had as a base the theoretical references already mentioned with emphasis on theories by Chanlat, Motta, and Peters. The knowledge of the researchers of the DL System in the company also contributed in the elaboration of instruments of research.

The data in the collected documents were analysed document analysis. The interviews were analyzed through content analysis.

First of all, the eleven initial categories were pre-determined on the basis of the previously selected aspects for the research. However, during the element classification, new aspects were encountered, leading to the establishing of seven more categories that were added to the formers. It is important to point out that all categories conformed to the principles suggested by Bardin (1977) - mutual exclusion, homogeneity, pertinence, objectivity and productivity. 
Nakayama, Pilla, Binotto, \& Silveira

\section{Findings}

\section{Analysis of the Telecommunications Sector, the Company and its DL System}

The telecommunications sector of which the company researched is a part of one of the sectors that have been going through many changes in the past year worldwide and especially in Brazil. The process of privatizing the sector and the following period of company acquisitions along with engagement in the commerce of competition have brought challenge of expanding boundaries to the operators.

It has also become perceivable that the companies in this sector re-formulated their internal policies. One that has been altered, for instance, is that of human resources. While there is the constant need to update the skills of employees to deal with the changes, there is an unstable organizational atmosphere marked by the dichotomy of satisfaction versus production. In this context, there is the added pressure for the accomplishment of the goals of the voluntary dismissal plans, requests for resignations, and the overload of work of those who remain.

The company where the research for this case study took place is one of the branches of a Brazilian telecommunications company, whose main activity is the providing of telephone services, local and national long-distance.

This enterprise differs a bit from the other Brazilian telecommunications companies as it was privatized into two phases. First, in 1996, it was partially privatized, and then in 1998, the rest of its capital was sold. However, in 2000, it was once again sold to its present owner and went through an organizational re-structuring. From a regional company it became a national one. Thus, its DL System had to be expanded and adapted to the needs of the other states where the company began to operate.

To this end, during the period of the research, two DL portals were put into operation: the new and the old. The latter already had a good number of services that were retained it the new improved model. The new system called "Education Portal" has an ability to adapt itself according to the user's profile by means of a password. However, it seems to be that the virtual communities of the DL system were more active in the past.

The very fact of there being two DL portals seems to be somewhat confusing to people, both employees and leaders. Some of the interviewees made several references concerning to the old portal and many might not even be aware of the existence of the new one.

This was verified, in one instance, when a leader requested recognition of distance course students. The new portal has a Mileage Program with this intent. Either at least some of the people are unaware of it or it is not entirely active. Another fact that was mentioned by employees and leaders is that the company does not acknowledge individual differences in the courses design for its. The new portal actually has a "user profile" tool for this purpose, but again, either the people ignore it or it is not entirely active.

One leader suggested that there should be rooms for DL in the company so that people could perform course activities outside their work areas to avoid interruptions annoyance colleagues and telephone calls. In compliance with the recommendations for the DL specialists, these rooms have already been created in buildings where there are a large number of employees, but many do not know of this fact.

Employees and leaders made identical requests for a better divulge of the DL information in the company. During the official inauguration of the DL System in the company (when it was still regional) in 1999, there was a big announcement publicising, which is still disseminated through 
the company. Yet, probably due to administration changes in the company and the policies of reducing costs in all areas, publicity about Human Resource projects (including the DL system) has been affected by budget cuts nationally.

Despite the expansion and restructuring of the company, it appears to be that recognition on the importance of DL has still not permeated the company's new strategy. The employees have the notion that the project goes on as an interesting idea that began during a former administration, but the new management has not yet "bought" the idea. To get them to do this has been one of the DL specialists’ main priorities.

\section{Perceptions of DL Specialists, Leaders and Employees}

The DL specialists proved to be a close-knit team that has been working together for some time. It is composed of young, qualified people who have a common purpose that is the improvement and expansion of the DL System not only in the company, but also beyond its boundaries.

The specialists enjoy their job and consider it a challenge. They are concerned with publicising the DL results and in try to bring them to the attention of administrators and customers.

None the less, the results are not being effectively shown to employees or leaders. Despite the efforts of the specialists, many achievements in DL are not internally perceived, confirming the fragility of the system in the process of communication and promotion of DL. According to an employee, the team's source is technology and that to promote Dl effectively it would be necessary for the team to "cease with the fascination over the tools". Therefore, the pressing challenge for the team is to improve the DL System by privileging the human aspects, regarding which, the system is most fragile.

The leaders interviewed had divergent views on some matters, such as participation and motivation. This reveals that the management team does not get have a unified approach to DL; a degree of disunity is typical in times of change as in the researched company's case. This is something well understood by the DL specialists who perceive that there are all kinds of leaders.

From the evidence, it would seem that the leaders need to be listened to by the company. In the interviews, they were asked to ponder the place of DL in the company and then contribute their thoughts, expectations, suggestions, and also to vindicate to their position.

The interviews indicate that the leaders are aware of their role in DL, but are not doing their part; that is fully admitted by them. In this case, some might not have up-to-date knowledge concerning alterations to their company' DL system, as for instance, the fact of the existence of a new portal (in the corporate environment), that courses were "recorded", and that the company provides specific rooms for the DL System. If the leaders do not know of this, neither would their subordinates and consequently they lose the opportunity of benefiting from DL system. The leaders also demand more DL announcements, but the ideal would be if they could be partners in the process.

According to the interviews, the employees' perceptions vary with the management style in their work areas. This style might favor DL or interfere it by direct influence with in the working environment. The leaders views was somewhat the same and at times did not agree with the views of the by DL specialists

In a general sense, the employees interviewed appeared to be quite satisfied with the DL system or had some complaints about it. Just like the leaders, they also demonstrated a need to be listened to by the company; there is in sufficient communication with the leaders, not only concerning the DL, but also in other Human Resource matters as well. 


\section{The Category Derivation Process}

The category derivation process begins with listing of initial categories of ideas or concepts relevant to the research. These key ideas are later regrouped into broader intermediary categories, which are further merged to form the final categories that make it possible to interpret and comprehend the results of study in a more representative manner. The derivation process is demonstrated in Table 1 . The categories with an asterisk $\left(^{*}\right)$ are those that were not originally stipulated but were added as the research progressed.

The key ideas of the initial categories are as follows:

1. Motivation: to do the DL courses arises from necessity, the will to increase knowledge or to update it or the challenge itself, without the need to re-locate; it depends on the individual himself.

2. Change in Behavior: The DL team is united. The people are more familiarized with DL and perceive the benefits. The leaders and employees did not notice changes in behaviour. They may vary depending on the worker's working area.

Table 1: Category Derivation Process.

\begin{tabular}{|c|c|c|}
\hline Initial Categories & Intermediary categories & Final Categories \\
\hline 1. Motivation & I. Personal attitudes before the DL & $\begin{array}{l}\text { A . DL personal as- } \\
\text { pects }\end{array}$ \\
\hline \multicolumn{3}{|l|}{ 2. Change in behavior } \\
\hline \multicolumn{3}{|l|}{ 3. Discipline * } \\
\hline \multicolumn{3}{|l|}{ 4. Resistance * } \\
\hline 5. Space \& time & $\begin{array}{l}\text { II. Differences between present learning and } \\
\text { DL }\end{array}$ & \\
\hline \multicolumn{3}{|l|}{ 6. Change in culture } \\
\hline 7. Desire & III. Present \& future DL view & \\
\hline \multicolumn{3}{|l|}{ 8. Symbolism } \\
\hline $\begin{array}{l}\text { 9. Communication \& } \\
\text { language }\end{array}$ & IV. Communication in the DL management & $\begin{array}{l}\text { B . DL organizational } \\
\text { aspects }\end{array}$ \\
\hline \multicolumn{3}{|l|}{ 10. Divulgation * } \\
\hline \multicolumn{3}{|l|}{ 11. Acknowledgement * } \\
\hline 12. Leadership & V. DL context in the company & \\
\hline \multicolumn{3}{|l|}{ 13. Cost reduction * } \\
\hline \multicolumn{3}{|l|}{ 14. Enterprise moment * } \\
\hline $\begin{array}{l}\text { 15. Individual particu- } \\
\text { larities }\end{array}$ & VI. DL pedagogical model & \\
\hline \multicolumn{3}{|l|}{ 16. Participation } \\
\hline \multicolumn{3}{|l|}{ 17. Consideration } \\
\hline 18. Apprenticeship & & \\
\hline
\end{tabular}

Source: elaborated by the authors through interviews 
3. Discipline: is fundamental for the DL System, yet it is quite challenging. The lack of it may be one of the causes of giving up courses and an unfavorable point of the DL. The work environment is prejudicial to course discipline.

4. Resistance: in the opinion of the specialists, some people will never adapt to the DL System. There are more resistant employees in DL (the older ones and those who believe they lose the chance to travel), although people seem to be becoming gradually less resistant.

5. Space \& Time: DL can bring saving of time and low costs for the company. It does not substitute for present interaction. It can overcome certain space and time barriers, but it demands discipline and planning. Its challenges are to offer a DL environment so that the person may not notice much change in space and time, negotiate arrangements with the company that people find time for the courses, deal with the difficulty the employees have with computer science, DL adaptation to the company, and find ways to avoid the delay in feedback. DL learning rooms had been created in buildings with large number of employees.

6. Change in Culture: DL brings forth a long-term cultural change. The DL culture is not yet disseminated in the company and within leaderships.

7. Desire: the specialists are keen to expand and improve the DL System. The leaders want a bigger investment, more courses, time, accompaniment, support, and DL promotion. The employees want the distance courses to be more informative to have more attractive contents and to be aligned with the company's strategic objectives; they also want better support by the leaders, greater involvement in more announcements about DL in the company, personalized courses, and mechanisms for making suggestions.

8. Symbolism: the specialists, leaders and employees see DL from the perspectives of economics (cost reduction) and modernization (development). To the specialists, DL represents their own field of work, which is challenging, a trend of the future and a source of professional fulfillment.

9. Communication and Language: DL system makes use of a series of tools to promote communication. However, because they operate at a distance, they have natural flaws that interfere in the communication process. To minimize these flaws, the company normally tests the tools. The channels are designed to be user friendly yet do not always seem so because the people using them sometimes lack information or initiative. The course language is direct, with plain colors, objective texts, clear audio-visual resources, and non-regional terms. Both leaders and employees approved the DL language; they realize that the company provides the tools, but find problems in communication.

10. Divulge: one specialist expects that everyone in the company may know DL system. Another would expect to see the leaders pass the word around. The leaders require DL promotion. Some employees pointed out the poor promoting in the company as, for example, the fact of being institutional and superficial.

11. Acknowledgement: the DL programs may make the employees feel more competent in the performance of their rules, but for this there must be a way to acknowledge the people that do these courses.

12. Leadership: all agree that the leaders should aid and support DL. Some leaders admit that they are not carrying out their role of support while some people believe that not all leaders see DL as something beneficial.

13. Cost Reduction: most of the people that were interviewed emphasized the possibility of the DL reducing training costs, mainly because there is no need for dislocation and travel. 
14. Enterprise Moment: the DL administration is affected by the moment of change the company is going through: it has brought an overload of work, challenging goals, organizational insecurity and uncertainty, pressure, and lack of time.

15. Individual Particularities: the specialists mentioned several techniques for handling the individual needs in DL of the distance learners. Some leaders perceive that the courses are offered according to the needs, but others believe that individuality has not been taken seriously. The employees do not see the company considering the differences in individual needs.

16. Participation: the specialists identify employees who are very participative in the courses and others who have greater difficulties or resistance. Most of the leader and employees believe that participation in DL courses is rather low and abstention high. The reasons might be: cultural features, overload of work, post-dismissal traumatic moment, and course schedules.

17. Reflection: may be done through virtual communities and discussion forums. Not all contents propose reflection (depends on the course). It might also depend on each individual's interest.

18. Apprenticeship: in general DL apprenticeship has worked well and tends to improve when there is a greater participation on behalf of the people themselves.

The ideas and information contained in these eighteen initial categories were next grouped under six intermediary categories, described bellow:

I. Personal attitudes before DL: people may assume different attitudes as a result of DL. Aspects such as motivation, change in behavior, discipline and resistance, vary with to each individual. In general, the company encounters difficulties in dealing with these aspects. Motivation is still low, not many changes in behavior have been verified. Discipline is a challenge and concept of DL still encounters resistance.

II. Differences between present learning and DL: DL may cause long-term cultural change and differs from the present learning. If on the one hand it overcomes some space and time barriers, gaining time for the student and reducing costs, on the other it has many challenges.

III. Present and future DL view: in the company at present, DL is seen as an economic opportunity (cost reduction) and a modernization opportunity (development). People expect to see an expanded and improved DL system in the future.

IV. Communication in the DL management: the DL management uses a series of tools for promotion and communication, yet there are existent flaws. The course language is adequate, but DL divulge of information and acknowledgement of the achievements of those who participate in the courses are poor.

V. DL context in the company: the DL management is affected by the moment of change the company is going through. The DL is being impaired as long as the leaders are not giving their support. Nevertheless, it is pertinent in this context the system' potential for cutting down training costs.

VI. DL pedagogical model: contains specific techniques in order to handle people's particularities; however, these techniques are not well perceived by the employees. The participation in DL courses is low and abstention high. Consideration does not occur in all courses and it happen more in virtual communities and discussion forums, depending on interest. Despite the brittleness of the model, the apprenticeship training, in general, in DL has produced good results.

The final step through of the content analysis in the category derivation process is the convergence of the intermediary categories into two final categories: DL personal aspects and DL organizational aspects. 
- Personal aspects result from the intermediary categories (personal attitudes before the DL; differences between present learning and DL; present and future DL view) that were the results of the regrouping of initial categories (motivation; change in behavior; discipline; resistance; space and time; change in culture; desire; symbolism). From these categories emerge the personal factors of the people regard to DL. These aspects are considered personal because they vary from person to person and express personal insights and opinions about the DL system.

- Organizational aspects result from the intermediary categories (communication in the DL management; the DL context in the company; the DL pedagogical model) resulted from the regrouping of initial categories (communication and language; divulge; acknowledgement; leadership; cost reduction; enterprise moment; individual particularities; participation; consideration; apprenticeship). From these categories come the organizational factors of the people with the DL. Organizational aspects refer to factors directly associated with the company's DL management in the human dimension, which depend on the decisions and actions of the organization and its DL specialists.

\section{Recommendations}

The intention of this research was to identify how the human aspects are considered in DL in a telecommunications company. This idea came from a study by Guerrero et al. (2002), which investigated the changes caused by DL implementation in the same organization and identify the human dimension one of the weakest perspectives.

The DL System of the company researched is an instrument used for the training and the development of its employees and more recently, mediator salesmen. It commenced in 1996, with the implementation of corporative TV. The official inauguration of the system was in 1999, and the expansion to its branches in 2002.

Besides the practical application of the DL concept, several classic instructional methods were identified in the company and noted by the authors. The use of printed material, television (corporative TV), telephones, and point-to-point videoconferencing was observed. The company also makes use of practically all the solutions of e-learning/WBT: e-mail, discussion list, newsgroups (in virtual communities), chat, WWW, video on demand, and web TV.

Other matters developed by the theoretical basis of this work were also checked in the company. From the DL professionals provide for instance, as mentioned by Cardoso \& Pestana (2001), the company with all the functions. There is the training analyst (specific for DL), the teacher, the schedule man (same analyst), and the pedagogue. This corroborates what the authors above mentioned affirmed, that the company does not necessarily need different professionals for each of these functions.

The DL System in the company, compared to the proposal made by Niskier (1999), reflects most of the phases of the author's model. The analysis of the company's system revealed that it has adequate knowledge sources, effective design and good quality presentation. The phases still to be improved are the interaction and learning environments, as stated in the interviews. Besides that, the integrated solutions mentioned by Cardoso \& Pestana and the technical DL project emphasized by Rego Jr. (2001) are factors which have been put into practice by the company.

Peters (2001) affirms that the transformation of a traditional learning process for DL is a consequence of an "industrialization" process of education. This fact was ascertained in the company as all interviews point out DL as a possible means of lowering cost. Thus, the intention to only increase institutional profits still persists as the primary motivation for using DL. In the case of the companies that use DL to qualification of their employees, part of the increase in overall profits comes from cost reduction. However, if organizational development were to be seen as a com- 
petitive factor, the profit would be a consequence of an increase in income favored by the organizational growth. For this to occur, it would become necessary to adopt a new learning model one designed to faster organization development rather than, merely to cut costs.

The research suggests that the subjects that need to be prioritized by the company are student communication with other students and tutors, collaboration in learning projects, learning results documentation, learning by means of simulations and experiments, and learning through the inclusion of virtual spaces in the system, which was confirmed in the interviews. It is stronger recommended that be developed collaborative learning.

Relating to constructivism/constructionism, it becomes perceivable that the company is not seeking priority for an educational model as knowledge is being treated like something prompt, with exception of virtual communities which constitutes space for knowledge creation. The cycle purposed by Valente (2000) “description-execution-reflection-refinement-description”, has stagnated in the reflection phase.

This research corroborates Peters' assertion that the problems in DL reflect the problems of classic education. According to those who were interviewed, the problems that traditionally appear in training are also carried over to DL. Thus, it is necessary that the DL system be improved to achieve learning outcomes that are more closely tied to the company's strategic plans prevent pedagogical deficiencies, besides giving individual and social needs of the human being more priority.

Perhaps one of the imperfections of the system is the type of distance courses offered by the company. It becomes clear that DL, despite its having a T\&D format, still has a focus on more technical and informative training, does not make development programs available. In the company researched, no course was identified would favour a real development for people.

In such a case, Carvalho (1994) says that the transmission of knowledge model must move towards to the construction of knowledge model. This was not verified as happening in the DL system of the company in point. An incipient construction of knowledge was observed in virtual communities and it important to encourage its development.

It was also observed that, in this company, the responsible professionals in DL are still very much technical (specialists). It is possible that this kind of technology may be prejudicial to distance training, which is a process that may commonly be seen as a systemic event. From the information given in the interviews, the conclusion was drawn that there has not been any feedback from the employees and leaders as to the DL team.

The DL system is not entirely integrated with other subsystems of the company, such as Human Resources/People Management. The suggestion is that the company uses the DL contribution for the retention of talents. The other HR programs may take advantage of the DL potential for the development of assemblage projects. Not only in HR, but also in general, the customer-furnisher relation may be improved.

Motta (1998) relates that companies affirm that the differential is not technology anymore, but HR. The differential of the DL case in the company researched still is technology. Even so, it is possible to witness move towards a more humanistic conception, confirming that the mechanistic paradigm is evolving towards a holistic paradigm.

In this new paradigm, the manager's role, according to Carvalho (1994), would be to provide conditions for developing competence, making changes and creating knowledge. That is an aspect and yet wanting in the company is admitted by its very own leaders, who are unable to understand the human aspects of their employees. 
Table 2: Chanlat's Human Aspects in the Company's DL

\begin{tabular}{|l|l|l|}
\hline \multicolumn{1}{|c|}{ Individual } & \multicolumn{1}{|c|}{ Investigated Aspects } & \multicolumn{1}{c|}{ Conclusion } \\
\hline Generic \& singular & Individual particularities & $\begin{array}{l}\text { The employees and some leaders do not } \\
\text { perceive the company as considering indi- } \\
\text { vidualities. }\end{array}$ \\
\hline Active \& reflexive & Participation \& reflection & $\begin{array}{l}\text { Participation in courses is low. Not all } \\
\text { courses propose reflection. }\end{array}$ \\
\hline With desire \& impulse & Desire & $\begin{array}{l}\text { Course language is adequate, yet there are } \\
\text { communication problems. }\end{array}$ \\
\hline Symbolic & Symbolism & $\begin{array}{l}\text { Greatest desire is for expansion and im- } \\
\text { provement of DL System. }\end{array}$ \\
\hline Space-temporal & Space \& time & $\begin{array}{l}\text { DL represents economy and moderniza- } \\
\text { tion. }\end{array}$ \\
\hline
\end{tabular}

Source: elaborated by authors through collected data.

The study of the human aspects of an enterprise permits a better understanding of people's behaviour. This research was not providing complete understanding of the human being, but to reveal the perceptions of a range of people (employees, DL specialists and leaders) of the company's DL System.

It has been pointed out that not all human aspects listed by Chanlat (1996) were a priority for the DL management in the company. Table 2 demonstrates some aspects that need of improvement.

In a general sense, it is believed that the aspects to receive priority by the company must be those that refer to DL that may be extrinsic to people. These aspects include as a priority communication, divulge, acknowledgement of those who participate, leadership, individual particularities, participation, and consideration.

After investigation and analysis of the collected data, the main positive aspects of DL in the company are as shown below:

- concerning about the human dimension

- the company provides excellent technical structure (equipment, net, etc.)

- several e-learning solutions are in use

- myths on the CBT are being dropped

- well-elaborated course language

- there is a well-structured technical project for DL

- integrated solutions (present + virtual) show results

As recommendations, we suggest for the company:

a) Introducing the DL project to administrators who might not yet know the system well so that it may be completely linked with the strategic plans of the company.

b) Elaborating a communication plan for the DL system that includes interaction between students, tutors, specialists and leaders. 
c) Elaborating an strategy for helping leaders to understand the DL system in their company so that they may perform their role of support in DL.

d) Improving the learning environment, encouraging collaborative projects, learning through simulations and experiments, performance in communities, and the construction of knowledge, independent of the type of contents in the courses. This is a way to accomplish a better constructivism/constructionism model, moving beyond the reflection phase in Valente's cycle.

e) Focusing on DL as a means of increasing income changing the mentality which currently sees it only as a cost reduction instrument.

f) Documenting and acknowledge students learning results, in an attempt to give validation to all who participate in distance courses. Suggestions are to introduce ceremonies, celebrations, and certificates, and reinforce the mileage program, which is unknown to many.

g) Developing and making available more informative training that contributes to personal development. The System will then be restricting only to punctual training. The change for the best will come with a broader functional formation.

h) Regarding the performance of DL specialists as internal consultants, improving internal relations between customer-furnisher, listen more to the people and stimulating their feedback about DL as a whole.

i) Devising a better approach in the Human Resource area of the company to establish partners that may benefit not only the DL but all subsystems of HR.

j) Developing a continuous promoting program concerning the DL system in the company.

It would be recommended as to academy research that further research be conducted in other enterprises, of all sizes, and dedicated to other activities that use DL for employee training. Future investigations with in depth study of one or more variables in this research will most certainly bring advances for the academic community. Other possibilities would be to investigate the evaluation on DL program results and the effectiveness of these programs in organizations.

\section{Conclusion}

The amplification of the limits of knowledge concerning DL and its implications will contribute to the better understanding of this methodology which is being used more and more in organizations, as its possibilities of application become known.

This research has attempted to broaden the knowledge about DL. Even so, it is necessary to point out that it has identified some factors that may have limited the study. One of them was the fact that the company was found to be in a period of change. This could had interfered with the collecting of data, as this was done over six months and some situations could have changed in the company in that time.

The number of people interviewed also limited the exploration of information obtained. Both the leaders and the employees interviewed might not faithfully represent all of the leaders and employees of the company. All the DL specialists in the company were interviewed, but even so, as it was qualitative research, there is no way measure their perceptions precisely. The fact that the researcher knew several of the interviewees may have caused the research to be skewed. Other leaders and employees from other branches of the company were not heard, focusing the study in only one Brazilian state. 
The lack of specific literature about the DL human aspects was also a limitation on this study. The writings for authors that generically work in the human dimension in organizations (like Chanlat and Motta) were used as the theoretical base.

Finally, the results of this study cannot be generalized as it concerns an analysis that considered a specific case of an organization that makes use of Distance Learning.

\section{References}

Bardin, L. (1977). Content Analysis. Lisboa: Edições 70. (in Portuguese).

Cardoso, F. C., \& Pestana, T. M. P. (2001). On line training (E-learning). In G. G. Boog (coord), Handbook of training and development: An operations guide ( pp. 205-220). São Paulo: Makron Books. (in Portuguese).

Carvalho, L. C. F. (1994). Strategic T \& D. In G. G. Boog (coord). Handbook of training and development - ABTD. (pp. 67-84). São Paulo: Makron Books. (in Portuguese).

Chanlat, J. (1996). For an anthropology of the human condition in the organizations. In J. Chanlat (coord.). The Individual in the organization: Forgot dimensions (v. 1, 3rd ed.), (pp. 21-45). São Paulo: Atlas. (in Portuguese).

Cruz, D. M. \& Moraes, M. (1998). Communications and information technologies for the distance learning in the integration university/enterprise. Florianópolis: PPGEP/UFSC. Retrieved 02 July 1999 (in Portuguese) from http://www.intelecto.net/ead/tecno1.htm

Fayol, H. (1989). Industrial and general management (10th ed.). São Paulo: Atlas. (in Portuguese).

Guerrero, R. P., Nakayama, M. K., Verdin, R.\& Pilla, B. S. (2002). The changes with the implementation of distance education systems in a telecommunications company. In the proceedings of the Encontro Nacional da Associação Nacional dos Programas de Pós-Graduação em Administração, 26. Salvador: ANPAD. (in Portuguese).

Kramer, E., \& Coester, W. (1999). Distance education: From theory to practice. Porto Alegre: Alternativa. (in Portuguese).

Mayo, E. (1933). The human problems of an industrial civilization. Londres: Routledge.

Moore, M. \& Kearsley, G. (1996). Distance education: A systems view. Belmont, USA: Wadsworth Publishing.

Motta, P. R. (1998). Organizational change: Theory and practice of innovation. Rio de Janeiro: Qualitymark. (in Portuguese).

Nakayama, M. K., Silveira, R. A. \& Pilla, B. S.. (2000). Virtual training: An application for the distance learning. In the proceedings of the Encontro Nacional da Associação Nacional dos Programas de PósGraduação em Administração, 24. Florianópolis: ANPAD. (in Portuguese).

Niskier, A. (1999). Distance education: The hopefulness technology. São Paulo: Edições Loyola. (in Portuguese).

Peters, O. (2001). Two structural changes in the distance education: Industrialization and digitalization. São Leopoldo: Unisinos. (in Portuguese).

Reed, M. (1998). Organizational theory: A historically disputed field. In S. Clegg, C. Hardy, \& W. R. Nord (original edition editors); M. Caldas, R. Fachin, \& T. Fischer (Brazilian edition editors). Handbook of organizational studies v. 1: Analysis Models and New Questions in Organizational Studies. ( pp.6198). São Paulo: Atlas. (in Portuguese).

Rego Jr, L. C. M.. (2001). E-learning. In G. G. Boog (coord). Handbook of training and development: An operations guide. (pp. 221-233). São Paulo: Makron Books. (in Portuguese).

Spodick, E. F. (1995). The evolution of distance learning. Hong Kong: University of Science \& Technology Library. Retrieved 23 November 2001 from http://sqzm14.ust.hk/distance 
Taylor, F. W. (1990). The scientific management principles. (8th ed.). São Paulo: Atlas. (in Portuguese).

Valente, J. A. (2000). Distance education: An opportunity for change in teaching. In C. Maia (coord). ead.br: Distance education in Brazil in the Internet era. São Paulo: Anhembi Morumbi. (in Portuguese).

Vargas, M. R. M.. (2000). Distance training through videoconference: The case of Embrapa. In the proceedings of the Encontro Nacional da Associação Nacional dos Programas de Pós-Graduação em Administração, 24. Florianópolis: ANPAD, 2000 (in Portuguese).

\section{Biographies}

Marina Keiko Nakayama is a professor and researcher at Business School at the Universidade Federal do Rio Grande do Sul. Her areas of interest include knowledge management, learning, and distance education as well as virtuality in Human Resources. She has published many papers in different areas of research and chapters in several books.

Bianca Smith Pilla is a doctoral student at Business School at the Universidade Federal do Rio Grande do Sul. She has developed studies on Distance Education area.

Erlaine Binotto is a Post-Graduate Student of the Centre of Studies and Research in Agribusiness, at the Universidade Federal do Rio Grande do Sul, Brazil and she is developing her doctoral thesis as a PhD student in the School of Natural and Rural Systems Management at The University of Queensland, Australia. This stage of her research is funded by the Brazilian government through Coordenação de Aperfeiçoamento de Pessoal de Nível Superior (Capes).

Ricardo Azambuja Silveira is a professor and researcher of Computer Science at the Universidade Federal de Pelotas. His research interest is the design and the use of virtual relationship elearning and Distance Education in Human Resource Development. 